\title{
Enfermería avanzada en el posgrado
}

\section{Post-grade Advanced Nursing}

Las (os) enfermeras(os) profesionales recién egresados de la carrera, o aún profesionales que llevan muchos años practicando su carrera muy exitosamente en un área específica se pueden preguntar iporqué la educación del postgrado es el paso lógico para el avance de la carrera profesional? ¿Como se justifica la búsqueda de una educación de postgrado que requiere de una inversión considerable de tiempo, de dinero, así como sacrificios y restricciones de las actividades del diario vivir que se exigen durante el estudio riguroso a nivel de postgrado?

La misión mas importante que define nuestro quehacer profesional es el de brindar un cuidado de salud de alta calidad, con seguridad, basado en evidencia y mejores prácticas. El logro de esta alta calidad en el cuidado y la práctica segura es apoyado por el desarrollo de evidencias empíricas y el establecimiento de mejores prácticas, lo cual en gran parte requieren de una formación universitaria a nivel de un postgrado que según su complejidad se debe realizar a nivel de especialización, de maestría y ultimadamente de doctorado.

El avance vertiginoso de innovaciones tecnológicas complejas en el cam- po de la salud, exige de una preparación de la (el) enfermera(o) con pensamiento crítico, bases científicas y humanísticas sólidas que le permita evaluar críticamente estas nuevas tecnologías y su aplicación a la población que sirve. Esta preparación científica y humanística va más allá de la preparación técnica. Este avance constante de innovaciones en el manejo del cuidado de los pacientes también exige que profesionales líderes de este cuidado profundicen el conocimiento en un área especializada. Este estudio especializado, que se ofrece de una manera curricular estructurada en universidades, debe preparar líderes con capacidad de enfrentar retos y cambios cada vez más complejos y de ser partícipe en la creación de políticas conducentes a la solución de los múltiples desafíos que enfrentan los sistemas de salud en todos sus niveles.

La formación de la maestría y el doctorado solidifica conocimientos, experiencias y habilidades para evaluar y conducir investigaciones y específicamente a nivel del doctorado para desarrollar modelos y teorías propias de la profesión que después de probar su aplicación a través de investigaciones empíricas se traduce en el desarrollo de conocimientos propios de la profesión.
La investigación en nuestra profesión en su mayor parte debe guiarse por preguntas generadas en la práctica del cuidado, las respuestas a estas preguntas se traducen en estudios que prueban intervenciones basadas en la evidencia científica y no en tradiciones. Se espera entonces que el cuidado basado en la evidencia resulte en mejores resultados de salud para el paciente (comprendiendo como paciente ampliamente en la profesión la comunidad, la familia y el individuo).

Muchas de las innovaciones en el cuidado de enfermería son invisibles porque las profesionales de enfermería no tenemos el estimulo suficiente para

\section{“La formación de la maestría y el doctorado solidifica conocimientos"}

publicar nuestros hallazgos y resultados. La academia a nivel del postgrado debe como meta estimular esta producción intelectual. 
La educación de postgrado es también esencial en la preparación de los docentes para la enseñanza de la profesión. Estas(os) docentes deben tener experiencia en una área especifica del conociendo (clínica, gerencial, informática, educativa u otras múltiples) que no solo se origina de la práctica extensa en el servicio pero del estudio especializado y estructurado que da un programa de postgrado. Las(os) docentes con esta preparación de postgrado retroalimentan los currículos de pre-grado y de postgrado actualizando los avances que constantemente están sucediendo en el área de la salud, enfatizando las habilidades de análisis crítico, liderazgo, crecimiento profesional y enseñando el conocimiento nuevo creado por las enfermeras investigadoras y otros profesionales.

Finalmente la educación de postgrado estimula el desarrollo de la autonomía profesional. La creación de modelos y teorías que guíen nuestra práctica, y las investigaciones que evidencian nuestro cuidado permite que poco a poco creamos esta autonomía. Por ejemplo el cuidado de pacientes con heridas y ostomías ha evolucionado gracias al desarrollo de este cuidado por la enfermera especializada en esta área, y en muchos sistemas de salud es la enfermera quien determina este cuidado.

No puedo terminar este importante mensaje sobre la educación de postgrado sin presentar el ejemplo de la (el) enfermera(o) en práctica avanzada que esta siendo poco a poco reconocida en países como los Estados Unidos, Australia y Canadá entre otros. Es ésta "la educación

de postgrado estimula

el desarrollo de la

autonomía profesional.

La creación de

modelos y teorías que

guíen nuestra práctica,

y las investigaciones

que evidencian nuestro

cuidado permite que

\section{poco a poco creamos}

esta autonomía."

(e) enfermera(o) quien ha logrado con mucho esfuerzo la expansión de su rol y aunque todavía con muchos obstáculos, la autonomía en la práctica profesional en muchas áreas del conocimiento (Atención primaria, cuidados críticos, enfermera partera, enfermera anestesista). Estas profesionales iniciaron esta expansión del rol con una educación post-básica, sin embargo reconociendo la complejidad de la educación especializada, ha llevado, por ejemplo en los Estados Unidos, a que desde el año 2000 la (el) enfermera(o) en práctica avanzada deba tener un nivel mínimo de educación de maestría con especialización en áreas especificas de conocimiento, en donde la flexibilidad y creatividad le han permitido adaptarse al cambio constante en la atención de salud. Ejemplos de este rol avanzado se ven en el profesional que se describe como "Nurse Practitioner" que en español no tiene una buena traducción, y yo le llamo enfermera(o) especializada(o). La expansión del rol comprende la preparación especializada en el manejo de problemas de salud a nivel primario, entendiendo como esto el conocimiento científico-teórico necesario para diagnosticar, interpretar, y manejar enfermedades agudas de baja complejidad y enfermedades crónicas estables, dentro del enfoque primario de la enfermera en mantenimiento de la salud (promoción de la salud y prevención de enfermedades) y el abordaje de los problemas no solo con un enfoque biológico sino considerando las complejidades del proceso salud-enfermedad desde lo psicológico/emocional, social, ambiental, cognitivo, y cultural. La (el) enfermera(o) en el cuidado crítico tiene una formación especializada con los mismos fundamentos de la enfermera en la atención primaria, en donde condiciones de salud del paciente cambian constantemente y que requieren terapias y monitorización continua y compleja, en la mayoría a nivel hospitalario; la(el) enfermera(o) anestesista esta preparada(o) para dar anestesia en muchos procedimientos quirúrgicos y la(el) enfermera(o) partera (u obstetra) para la atención directa e independiente de la madre, especialmente de bajo riesgo, durante su etapa peri natal.

Por lo que invito a la comunidad a fortalecer el Posgrado en eEnfermería

Mtra. Pilar Bernal de Pheils Escuela de Enfermería de la Universidad de San Francisco, California. EUA. 